\title{
Automation for Measuring Compaction Force in Root Canal Obturation
}

\author{
Ratnakar R Ghorpade* \\ Department of Mechanical Engineering, MIT World Peace University, India
}

*Corresponding author: Ratnakar R Ghorpade, Assistant Professor in Mechanical Engineering Department, MIT World Peace University, Kothrud, Pune, India

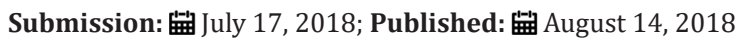

\begin{abstract}
Root canal treatment (RCT) is repairing and saving the badly decayed or infected tooth. Endodontic means treating tooth from inside and Obturation is a process of complete filling and sealing of 3D root canal space with gutta percha as biocompatible sealing material against bacterial growth. The main cause of Endodontic treatment failure is the incomplete sealing of the root canal. The degree of endodontic success depends to greater extent on mechanical sealing of root canal cavity with gutta percha. One of the means to quantify measures for evaluating Root canal success is to get compaction loading pattern during Obturation and corresponding Radio-visio-graph. Current paper discusses a brief review and automation used in the Obturation process to extract experimentally the compaction load pattern on C2 curvature tooth.
\end{abstract}

Keywords: RCT; Endodontics; Obturation

\section{Introduction}

In dental practice, failure of root canal treatment is mainly because of incomplete obturation [1]. It includes formation of voids, under-filling \& over-filling etc. Many factors are responsible for this failure, so the mechanical factors such as Thermal Behavior of Gutta Percha, Properties of Sealers and Compaction Force during obturation, Method and Techniques of Root filling etc.are considered to be important. The extrusion temperature affects the visco-elastic properties of Gutta-Percha during the injection, cooling, and compaction process in the root canals [2]. The mean specific heat value for gutta-percha was evaluated to be $0.94+$ or $-0.09 \mathrm{~J} / \mathrm{g} \mathrm{s}^{\circ} \mathrm{C}[3]$. The compaction force needed providing a significant increase in the diameter of heated gutta-percha specimens should be greater than $3 \mathrm{~kg}$ [4]. Values ranging from $1-3 \mathrm{~kg}$ are accepted as safe when condensing gutta-percha and avoiding vertical fractures [5]. Increase of loading didn't generate radiographic improvement in the final result of the filling but leads to defects like appearance of fissure lines and/or incomplete cracks [6]. Saatchi M \& Etesami L [7] reported the force used during spreader placement. An apical pressure was then applied on the spreader and increased without rotation until $1.5 \mathrm{~kg}$. Ivan Katalinic et al. [5] has presented Spreader design, speed of penetration and loading force, canal flare and root dimensions may affect the formation of vertical root fractures. Values ranging from 1 to $3 \mathrm{~kg}$ are generally accepted as safe when condensing gutta-percha and vertical fractures will not occur. Vimala $N$ [8] in this study, themesio-buccal roots which were radiographically evaluated for curvature in the canal, as per Schneider's technique. Guimarães MRFSG et al. [6] in their study utilized a device (for load application) coupled to the UTM, the forces were recorded by the machine M-Test software and converted into the graphs so as to analyze the applied forces in $\mathrm{kg}$.

\section{Dental Root Canal Process Automation Experiment}

In the current study, an experiment was performed on extracted tooth sample with $\mathrm{C}_{2}$ canal curvature. Tooth is cleaned and shaped exactly to the required size (i.e. termed as biomechanical preparation) using $4 \%$ taper files. The obturation is done using vertical compaction with down-pack method using proposed technique (i.e. Heat, Compaction and Vibration). During obturation on a tooth, a compaction load signature is captured that shows load vs time chart for a complete obturation cycle. Also the root canals of obturated tooth is analyzed based on Radio Visio-Graphs (RVG's) which is considered as one of the filling assessment technique. It has been seen that optimum Compaction force is $6.52365 \mathrm{~N}$

\section{Result and Discussion}

Total 19 events were noted as shown in the Figure 1. Maximum compaction force of $0.664 \mathrm{~kg}(6.52 \mathrm{~N})$ was noted for $15^{\text {th }}$ event. The compaction force of $0.506 \mathrm{~kg}(4.95 \mathrm{~N})$ was noted for $6^{\text {th }}$ event. Final obturation in a canal shows complete and adequate filling.Knowing the quality of filling one can correlate the load value noted in the obturation of that canal. Dentists can follow ideal loading pattern for a tooth having a particular curvature type (viz $\mathrm{C}_{1}, \mathrm{C}_{2}$, or $\mathrm{C}_{3}$ ) to get intact and dense filling.During obturation, a compaction load signature was captured that shows load vs time chart for a complete 
obturation cycle for a tooth. The compaction load must be carefully applied to achieve complete 3D filling of biomechanically prepared canal space. Maximum compaction force of $0.664 \mathrm{~kg}(6.52 \mathrm{~N})$ was noted for $15^{\text {th }}$ event.

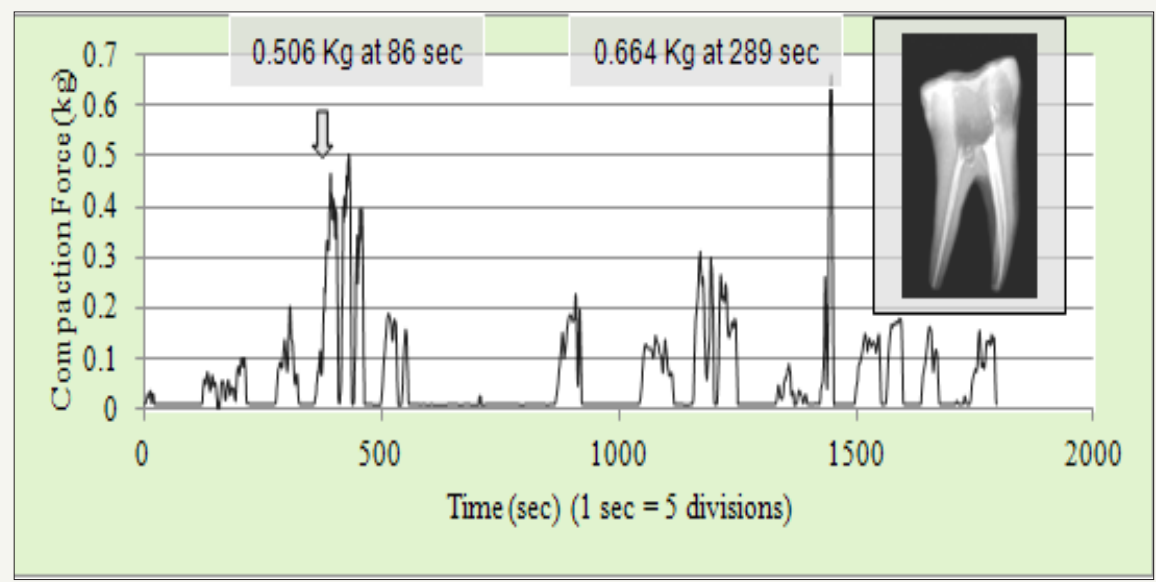

Figure 1: Compaction load pattern in obturation.

\section{References}

1. Tsukada G, Tanaka T, Torii M, Inoue K (2004) Shear modulus and thermal properties of GP for root canal filling. Journal of Oral Rehabilitation 31(11): 1139-1144.

2. Juhea C, Seung HB, In BL (2011) Rheological characterization of thermoplasticized injectable gutta-percha and resilon. J Korean Acad Conserv Dent 36(5): 377-384.

3. Marcus RM, David WB, James KB (2006) A comparison of thermal properties between gutta-percha and a synthetic polymer based root canal filling material (Resilon). Journal of Endodontics 32(7): 683-686.

4. Tanomaru FM, Geraldine FS, Juliane MGT, Bier CA (2007) Evaluation of the thermoplasticity of different gutta-percha cones and Resilon®. Australian Endodontic Journal 33(1): 23-26.
5. Ivan K, Baraba A, Glavicić S, Segović S, Anić I, et al. (2013) Comparison of vertical forces during root canal filling with three different obturation techniques. Coll Antropol 37(3): 895-899.

6. Guimarães MRFSG, Gomide HA, Oliveira MAVC, Biffi JCG (2011) Analysis of forces developed during root canal filling by different operators. Dental Press Endod 1(1): 52-57.

7. Saatchi M, Etesami L (2006) Comparison of spreader penetration during lateral compaction of 0.04 and 0.02 tapered gutta-percha master cones. Journal of Dentistry, Tehran University of Medical Sciences, Tehran, Iran 3(3): 112-116.

8. Vimala N. Comparative study of strain generated during lateral condensation using stainless steel and nickel titanium finger spreaders. Endodontology, Department of Conservative Dentistry and Endodontics, Padmashree Dr. DY Patil Dental College and Hospital, Navi Mumbai, India, 400706, pp. 106-112.

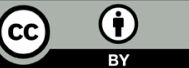

Creative Commons Attribution 4.0 International License

For possible submissions Click Here
Submit Article

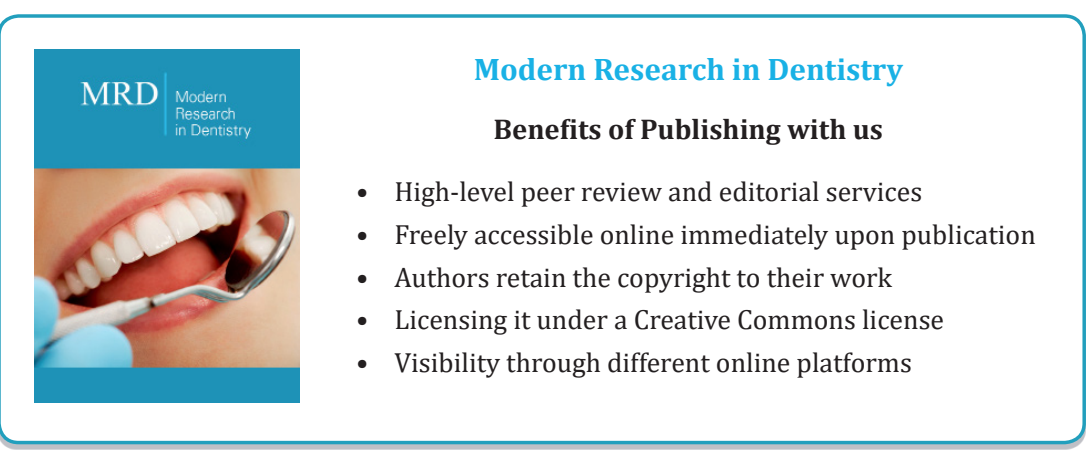

